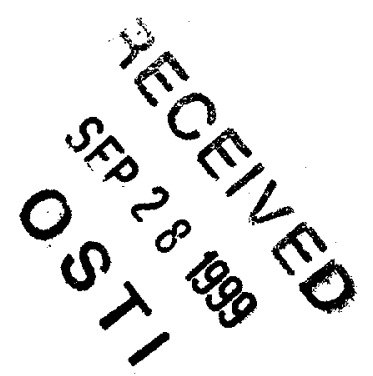

\title{
THE PROTEIN'S ROLE IN TRIPLET ENERGY TRANSFER IN BACTERIAL REACTION CENTERS
}

\author{
P. D. Laible ${ }^{1,2}$, D. K. Hanson ${ }^{1}$, M. C. Thurnauer ${ }^{2}$, and M. Schiffer ${ }^{1}$ \\ ${ }^{1}$ Center for Mechanistic Biology \& Biotechnology and ${ }^{2}$ Chemistry Division, \\ Argonne National Laboratory, 9700 S. Cass Ave., Argonne, IL 60439 USA
}

Key words: carotenoids, energy dissipation, EPR, sequence analysis, site-directed mutagenesis

\section{Introduction}

When photosynthetic organisms are subjected to high-light conditions in nature, electron transfer becomes blocked as the rate of conversion of light into charge-separated states in the reaction center (RC) exceeds the capacity of the soluble carriers involved in cyclic electron transfer. In that event, a well-characterized $\mathrm{T}_{0}$-polarized triplet state ${ }^{\mathrm{T}} \mathrm{P}$, is formed on the primary donor, $\mathrm{P}$, from the $\mathrm{P}^{+} \mathrm{H}_{\mathrm{A}}{ }^{-}$state (reviewed in [1]). In an aerobic or semi-aerobic environment, the major role of the carotenoid (C), also bound by the $\mathrm{RC}$, is to quench ${ }^{\mathrm{T}} \mathrm{P}$ prior to its sensitization of the ${ }^{1} \Delta_{\mathrm{g}}$ singlet state of oxygen -- a potentially damaging biological oxidant. The carotenoid performs this function efficiently in most bacterial RCs by rapidly accepting the triplet state from $\mathrm{P}$ and dissipating this excitedstate energy into heat through internal conversion. The lowest-lying triplet states of $P$ and the carotenoid are sufficiently different that ${ }^{\mathrm{T}} \mathrm{P}$ can promote oxygen to its excited singlet state whereas ${ }^{\mathrm{T}} \mathrm{C}$ can quench the ${ }^{\mathrm{T}} \mathrm{P}$ state (reviewed in [2]).

In the $\mathrm{RC}$ structure, the carotenoid, either 1,2 dihydroneurosporene in Rhodopseudomonas (Rps.) viridis [3] or spheroidene in Rhodobacter (Rb.) sphaeroides $[4,5,6]$, is located near bacteriochlorophyll monomer $B_{B_{\text {, }}}$ about $15 \AA$ from the periplasmic surface of the complex. It is bound in a high-energy $15-15^{\prime}$-cis configuration that is responsible for many of its spectroscopic properties [5]; the cis bond is within van der Waals distance of the edge of the macrocycle of $B_{B}(3.7 \AA)$ and is $10 \AA$ from the nearest atoms of $P$. The carotenoid interacts with amino acids of the $A, B$, and $\mathrm{C}$ helices as well as those of a short interhelix connecting loop ( $c d$ segment). Its environment is relatively hydrophobic; six tryptophan residues and eight phenylalanine residues are located within $5 \AA$ of the carotenoid [5]. The triplet energy transfer reaction is presumably controlled by the exchange
mechanism described by Dexter [7] which requires near orbital overlap between the donor and acceptor species. Because the distance between $P$ and the carotenoid is too large to allow the orbital overlap required for efficient exchange, the transfer involves $B_{B}$ as a bridging molecule [8]. The transfer process is thermally activated; the observation of the ${ }^{\mathrm{T}} \mathrm{C}$ signal (indicative of excited state transfer) at temperatures between 95 and 150 $\mathrm{K}$ is dependent upon the triplet energy level of the molecule bound at the $\mathrm{B}_{\mathrm{B}}$ site [8].

The carotenoid is "protective", i.e., able to quench triplet states from $\mathrm{P}$, in RCs of $R b$. sphaeroides and $R b$. capsulatus and Rhodospirillum (Rsp.) rubrum. We have determined the rate constants for triplet energy transfer in these three species and show in this paper that they vary widely. In light of the overall sequence, structural, and functional homology between the RC complexes of these species, it is likely that small 


\section{DISCLAIMER}

This report was prepared as an account of work sponsored by an agency of the United States Government. Neither the United States Government nor any agency thereof, nor any of their employees, make any warranty, express or implied, or assumes any legal liability or responsibility for the accuracy, completeness, or usefulness of any information, apparatus, product, or process disclosed, or represents that its use would not infringe privately owned rights. Reference herein to any specific commercial product, process, or service by trade name, trademark, manufacturer, or otherwise does not necessarily constitute or imply its endorsement, recommendation, or favoring by the United States Government or any agency thereof. The views and opinions of authors expressed herein do not necessarily state or reflect those of the United States Government or any agency thereof. 


\section{DISCLAIMER}

Portions of this document may be illegible in electronic image products. Images are produced from the best available original document. 
changes in the protein

environment surrounding the $P$, $B_{B}$, and $C$ cofactors are responsible for the observed differences in the rates of reactions associated with the carotenoid. We also show that site-specific mutants of the $R b$. capsulatus $\mathrm{RC}$ can begin to mimic species-specific differences in the rates of the triplet energy transfer reaction.

\section{Procedure}

Mutants were constructed and cultures were grown as described previously [9]. Chromatophore samples were prepared as detailed in [10].

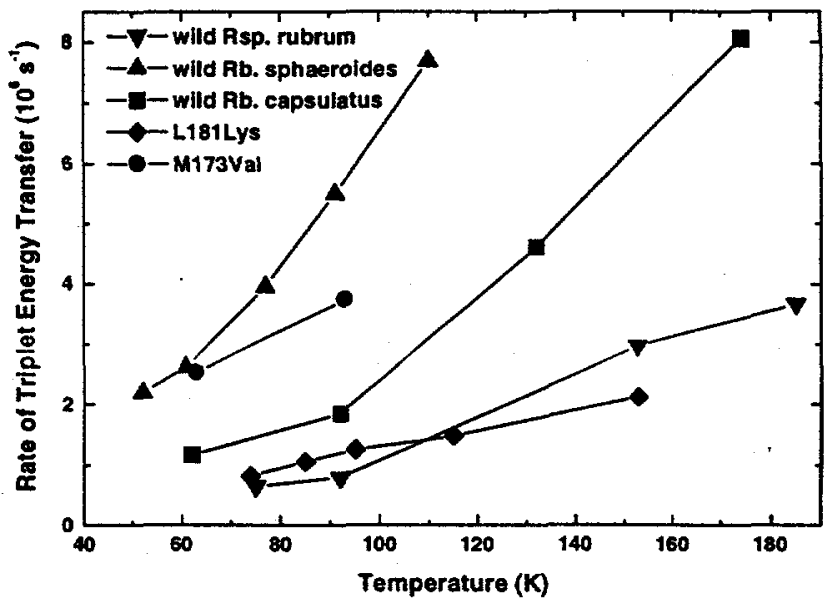

Figure 1. Temperature dependence of rates of triplet energy transfer to the carotenoid in selected RCs.

Direct-detection, continuous-wave time-resolved electron paramagnetic resonance spectroscopy (TR-EPR) was conducted using a Bruker ESP300E spectrometer and E046XK-T bridge equipped with an Oxford cryostat, low Q "split-ring" cavity, and broad band amplification resulting in electronically-limited EPR response times of $<50$ ns. Laser excitation was achieved through the second harmonic output of a YAG laser (Quantel). Transient spectra were recorded as described earlier [11]. Kinetics were directly recorded on a $175 \mathrm{MHz}$ digital oscilloscope (LeCroy).

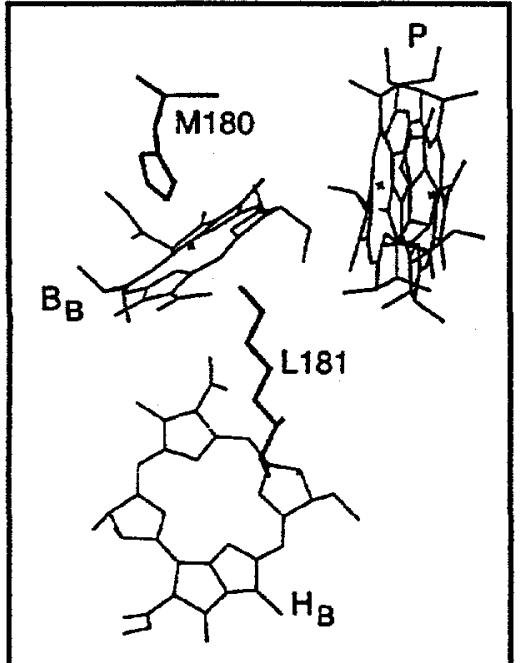

Figure 2. Molecular model of hexacoordination of the $\mathrm{Mg}$ of $\mathrm{B}_{\mathrm{B}}$ by L181Lys.

\section{Results and Discussion}

We have used TR-EPR to measure the rates of triplet energy transfer to the carotenoid in RCs from three different species of purple photosynthetic bacteria -- $R b$. sphaeroides, Rb. capsulatus, and Rsp. rubrum (Fig. 1). $\mathrm{RCs}$ of $R b$. sphaeroides are most efficient in performing this quenching reaction; ${ }^{\mathrm{T}} \mathrm{C}$ can be observed at $40 \mathrm{~K}$ in the $R b$. sphaeroides RCs, but cannot be seen in $R b$. capsulatus RCs until the temperature is raised to $70 \mathrm{~K}$. RCs of Rsp. rubrum are even less efficient. At $100 \mathrm{~K}$, rates of triplet energy transfer in spheroidene-containing wild-type RCs are $6.8 \times 10^{6} \mathrm{~s}^{-1}$ in $R b$. sphaeroides and 2.3 $\times 10^{6} \mathrm{~s}^{-1}$ in $R b$. capsulatus; the rate in spirilloxanthincontaining wild-type $R s p$. rubrum RCs is $1.0 \times 10^{6} \mathrm{~s}^{-1}$.

We had previously constructed a family of strains that carry site-specific mutations at residues $L 181$ Phe and M208Tyr, located near $P, B_{A}$, and $B_{B}$. We determined the efficiency of triplet energy transfer from $P$ to $C$ for the members of the mutant family using light-modulated EPR spectroscopy [10]. At temperatures $\geq 70 \mathrm{~K}$, we observed reduced signals from the carotenoid in most of the RCs with L181 substitutions. In particular, triplet transfer efficiency was reduced in all $\mathrm{RCs}$ in which a lysine at L181 donates a sixth ligand to $\mathrm{B}_{\mathrm{B}}$ (Fig. 2). We speculated that the change in the transfer rate is caused by the change in the planarity or position of $B_{B}$ 
that is caused by the addition of this sixth ligand [10], which would decrease the electronic overlap between $P$ and $B_{B}$. Determination of the temperature dependence of the rate of triplet transfer shows that the L181Lys mutation causes a decrease in the efficiency of this reaction (KY strain; Fig. 1) such that it more closely resembles that of the Rsp. rubrum $\mathrm{RC}$.

\subsection{Molecular modeling and rational design of mutant.}

To determine the sequence variations that might contribute to the threefold increase in triplet transfer efficiency in RCs of $R b$. sphaeroides versus those of $R b$. capsulatus (Fig. 1), we aligned the sequences of RC genes from 22 species of photosynthetic bacteria and analyzed the variability of residues that were located within $5 \AA$ of either $\mathrm{B}_{\mathrm{B}}$ or $\mathrm{C}$ in the $R b$. sphaeroides $\mathrm{RC}$ structure [5]. The sequence alignments and structure analysis suggested residue $\mathrm{M} 173$ as a candidate for mutation. M173 is either

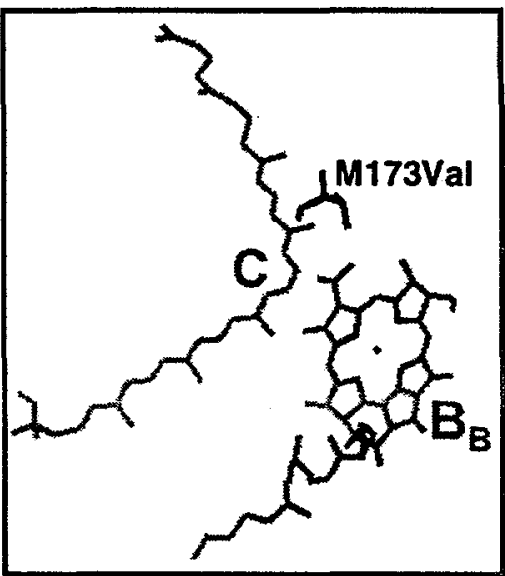

Figure 3. Position of M173Val relative to $C$ and $B_{B}$ in the structure of the native $R b$. sphaeroides RC [5]. a proline or a valine in the 22 sequences that were compared. M173Pro is an obvious difference that distinguishes the RCs of $R b$. capsulatus from those of several other species of purple non-sulfur bacteria, including $R b$. sphaeroides, that have Val at this site. This residue is positioned such that it could influence the electronic properties of $\mathrm{B}_{\mathrm{B}}$ and/or C; the position of M173Val is shown in Figure 3. In the Rb. sphaeroides $\mathrm{RC}$

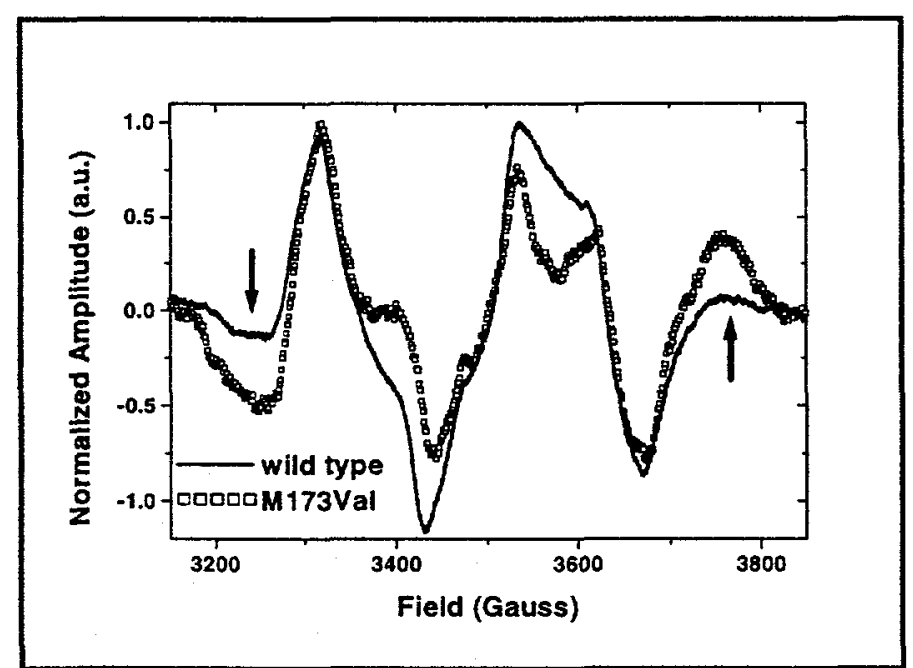

Figure 4. Time-resolved EPR of the triplet state of wild-type and M173V RCs of Rb. capsulatus at 100 $\mathrm{K}, 200 \mathrm{~ns}$ following a $532 \mathrm{~nm}$ laser flash. Differences in the spectra are due to a greater proportion of ${ }^{\mathrm{T}} \mathrm{C}$ in the M173V RCs, indicating increased transfer efficiency. Although ${ }^{\mathrm{T}} \mathrm{C}$ and ${ }^{\mathrm{T}} \mathrm{P}$ overlap substantially, the $\mathrm{Z}$ features of ${ }^{\mathrm{T}} \mathrm{C}$ (indicated by arrows at $3250 \mathrm{G}$ and $3750 \mathrm{G}$ ) are uniquely resolved and used to monitor arrival of the excited state on $C$. The signals in the center of the spectra are overlapping triplet features of ${ }^{\mathrm{T}} \mathrm{P}$ and ${ }^{\mathrm{T}} \mathrm{C}$. structure [5], M173Val is located within $\sim 4 \AA$ of the $15,15^{\prime}$-cis bond of $C$, and it is about $4.2 \AA$ from the closest substituent of $B_{B}$.

We constructed the sitespecific M173Pro-Val mutant of $R b$. capsulatus and have subjected it to preliminary TR-EPR analysis (Figures 1 and 4). These data show that at $100 \mathrm{~K}$ triplet transfer is $>2.5$-fold faster in this mutant than the same triplet transfer reaction in the wild-type RC of $R b$.

capsulatus. Therefore, for the first time, rational design has been used to produce an $\mathrm{RC}$ that is significantly more efficient in the photo-protection process.

Prolines add rigidity to the polypeptide, therefore the substitution of proline by a valine might be expected to add flexibility to the chain in this region of the mutant RC. That flexibility might lead to changes in the relative positions of the cofactors involved in the triplet transfer reaction, which would alter its efficiency 
$[7,12]$. Modeling of the opposite Val-Pro mutation in the $R b$. sphaeroides $\mathrm{RC}$ structure [5] shows that it would be easily tolerated, requiring no change in the dihedral angles.

Thus, it is not expected that the Pro $\rightarrow$ Val switch in Rb. capsulatus would be problematic. Instead of an increase in flexibility, it is therefore likely that the size of the side chain at this position may be more important in influencing the rate of the transfer reaction because it may modify the position of $B_{B}$, thus determining the extent of its orbital overlap with $\mathrm{P}$. Additional mutants -- to Ala, Ile, and Thr -- will test this hypothesis. If this hypothesis is valid, we would not expect to see a change in the transfer rate with the substitution of Ala for Pro. Thr is similar to Val in that it also has a branched side chain, but it is more polar. The Ile substitution, one $\mathrm{CH}_{2}$ unit longer than Val, might be too large and could reduce the rate (as seen previously with the L181Lys mutation) by causing a shift in the position of $B_{B}$, thus altering its orbital overlap with $P$. These constructions are in progress.

In summary, site-specific changes within the $\mathrm{RC}$ protein of $R b$. capsulatus can be designed to increase or decrease the efficiency of transfer of the triplet state from $\mathbf{P}$ to the carotenoid. These changes within one species can begin to mimic interspecies differences in the rates of this energy transfer reaction.

\section{Addendum}

We thank Raj Pokkuluri for the structure figures. This work was supported by the U. S. Department of Energy, Offices of Biological and Environmental Research (PDL, DKH, MS) and Basic Energy Sciences, Division of Chemical Sciences (PDL, MCT) under Contract No. W-31-109-ENG-38, and by Argonne National Laboratory Research and Development funds.

\section{References}

1. Thurnauer, M.C. (1979) Rev. Chem. Int. 1,197-230.

2. Cogdell, R.J., and Frank, H.A. (1987) Biochim. Biophys. Acta. 895, 63-79.

3. Deisenhofer, J., Epp, O., Sinning, I., and Michel, H. (1995) J. Mol. Biol. 246, 429457.

4. Ermler, U., Fritzsch, G., Buchanan, S.K., and Michel, H. (1994) Structure 2, 925936.

5. Arnoux, B., Gaucher, J.-F., Ducruix, A., and Reiss-Husson, F. (1995) Acta Cryst. D51, 368-379.

6. Stowell, M.H.B., McPhillips, T.M., Rees, D.C., Soltis, S.M., Abresch, E., and Feher, G. (1997) Science 276,812-816.

7. Dexter, D.L. (1953) J. Chem. Phys. 21, 836-850.

8. Frank, H.A., Chynwat, V., Hartwich, G., Meyer, M., Katheder, I., and Scheer, H. (1993) Photosyn. Res. 37,193-203.

9. DiMagno, T.J., Laible, P.D., Reddy, N.R., Small, G.J., Norris, J.R., Schiffer, M., and Hanson, D.K. (1998) Spectrochim. Acta A, in press.

10. Laible, P.D., Chynwat, V., Thurnauer, M.C., Schiffer, M., Hanson, D.K., and Frank, H.A. (1998) Biophys. J. 74, 2623-2637.

11. Utschig, L.M., Greenfield, S.R., Tang, J., Laible, P.D., and Thurnauer, M.C. Biochemistry 36, 8548-8558.

12. Lamola, A.A. (1969) in Energy transfer and organic photochemistry (Lamola, A.A., Turro, J.J., Leermakers, P.A., and Weissberger, A., eds.) pp. 17-132, Interscience Publishers. New York. 